\title{
DAM BREAK ANALYSIS USING BOSS DAMBRK
}

\author{
Anila C. George ${ }^{1}$, B. Thulasidharan Nair ${ }^{2}$ \\ ${ }^{1}$ Assistant Professor, Department of Civil Engineering, Federal Institute of Science and Technology, Mookkanoor, \\ Angamaly, Kerala- 683572 \\ ${ }^{2}$ Associate Professor, Department of Civil Engineering, College of Enineering Trivandrum, Trivandrum, Kerala- \\ 695016
}

\begin{abstract}
Dams are constructed to serve a variety of purposes such as supply of drinking and irrigation water, generation of electric power, flood protection etc... However a dam break may result in high flood waves traveling along a valley at quite high speed. The intensity of the catastrophic failure of dams varies depending on the extent of inundated area, size of the population under risk and the warning time available. The present study deals with the Dam Break Analysis of Thenmala Dam of Kerala State, India. As a part of the work, the maximum precipitation and maximum flood have been evaluated using the Gumbel's and Clark's method respectively. The final analysis is done using the software BOSS DAMBRK for evaluating the extent of inundation, travel time and velocity of downstream progressing water.
\end{abstract}

Keywords: BOSS DAMBRK; maximum precipitation; maximum flood; Gumbel's method; Clark's method

\section{INTRODUCTION}

Catastrophic flash flooding occurs when a dam is breached and the impounded water escapes to the downstream valley through the breach leading to its uncontrolled release and can have large impacts on the land and communities downstream of the dam. The failure of a dam may result in flood waves travelling at quite high speeds. With such destructive forces in action, there will be inevitable loss of lives and destructions caused to the infrastructure. Along with these factors, there will be increased movement of sediments and debris mainly causing spreading of pollutants. In the below sections, a brief overview of the software, methodology used in the dam break analysis and the analysis results are discussed.

\section{METHODOLOGY AND MATERIALS}

For the study, estimation of maximum precipitation and maximum flood forms the base. Maximum precipitation is evaluated using the Gumbel's Method and the corresponding flood is evaluated using the Clark's method. The maximum flood is then routed using the reservoir routing method known as Modified Pul's method to finally obtain the time - elevation - flood outflow relation which helps in understanding the sufficiency of the provided spillway.

The next step is the analysis of the problem using the BOSS DAMBRK software. This portion of the study makes use of breach description values; reach description values; reservoir description values; inflow hydrograph values and boundary conditions as inputs. DAMBRK simulates the failure of the dam together with the movement of the dambreak flood wave through the downstream channel.

\subsection{Study Area}

Thenmala dam, together with the adjoining Kallada river

basin of Kerala state, India is selected as the study area. The study area is approximately 542. 1 square kilometers in area and lies between latitude of $8^{0} 9^{0}$ to $9^{0} 17^{0}$ and a longitude of $76^{0} 16^{0}$ to $77^{0} 24^{0 .}$

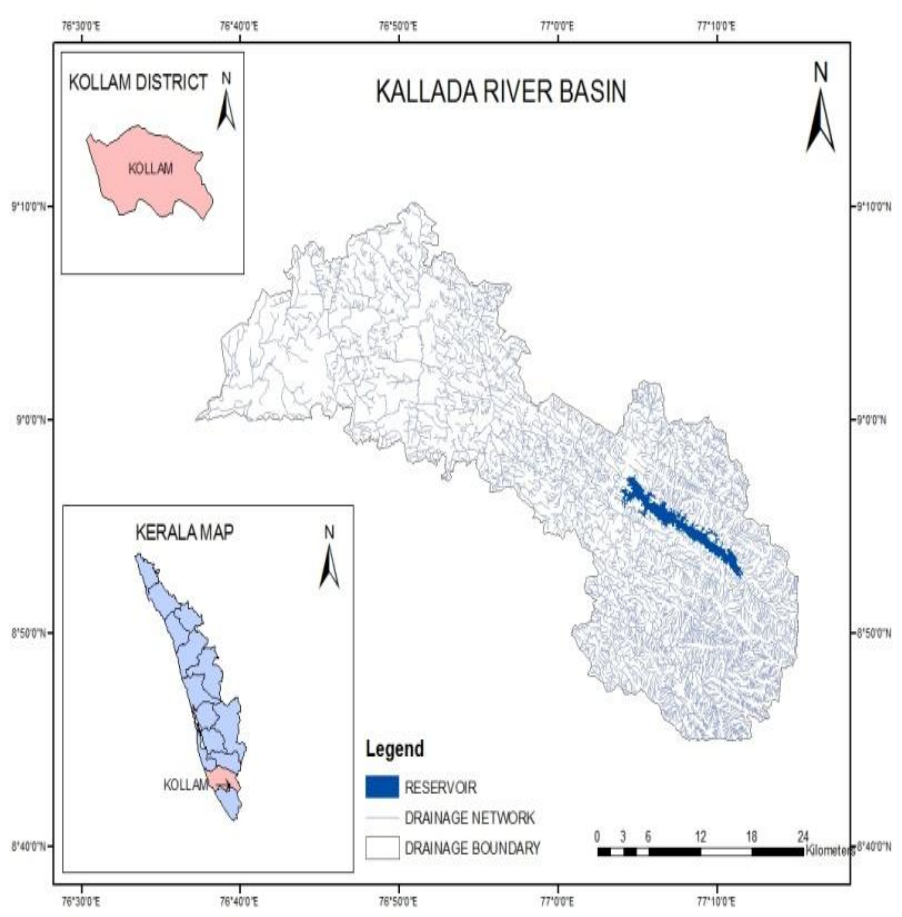

Fig. 1: Kallada River Basin

The dam characteristics include:

- FRL

- MWL

- Spillway crest level

- Top of dam crest level

- Height of dam

$$
\begin{aligned}
& =115.82 \mathrm{~m} \\
& =116.73 \mathrm{~m} \\
& =106.68 \mathrm{~m} \\
& =118.87 \mathrm{~m} \\
& =85.35 \mathrm{~m}
\end{aligned}
$$



- $\quad$ Length of dam
$=335 \mathrm{~m}$
- Live storage capacity$$
=487.9 \mathrm{Mm}^{3}
$$

\subsection{Data Used}

The data collected for the study includes the daily rainfall data for the past 30 years $(1982$ - 2011) from the Indian Meteorological department. Survey of India toposheets (58 $\mathrm{G} 4,58 \mathrm{H} 2,58 \mathrm{D} 9$, and $58 \mathrm{C} 16$ ) are also made use for digitizing the boundary as well as for identifying the drainage network of the study area. ASTER digital elevation model is also used to obtain the river cross sections.

\subsection{Software Used}

- $\quad$ ArcGIS 9.1

- BOSS DAMBRK

\section{DETERMINATION OF MAXIMUM PRECIPITATION AND FLOOD}

Rainfall data is required for the computation of maximum precipitation and the corresponding peak discharge. Also, ASTER digital elevation model is been made use to obtain the downstream channel cross sections.

\subsection{Maximum Precipitation}

The daily rainfall values are analysed using the Gumbel's method to obtain the maximum precipitation. The cumulative rainfall values are found out for 1-, 2-, 3-days respectively and the maximum value for each month are considered. Mean and standard deviation for each time period is calculated in order to find out maximum intensities of rainfall for different durations. Intensity - Duration Frequency curves are then plotted for different return periods to find out the maximum precipitation corresponding to the time of concentration. The time of concentration $\left(\mathrm{T}_{\mathrm{c}}\right)$ used above was calculated using the Kirpich's equation and is obtained as 1.5 hours.

$$
\mathrm{T}_{\mathrm{C}}=0.0195 \mathrm{~L}^{0.77} \mathrm{~S}^{-0.385}
$$

where $\mathrm{L}$ is the length of the main water course upstream of the dam in kilometers $(44.78 \mathrm{~km})$ and $\mathrm{S}$ is the slope of the study area ( 1 in 33). The obtained IDF curves for the basin are shown in Figure 2.

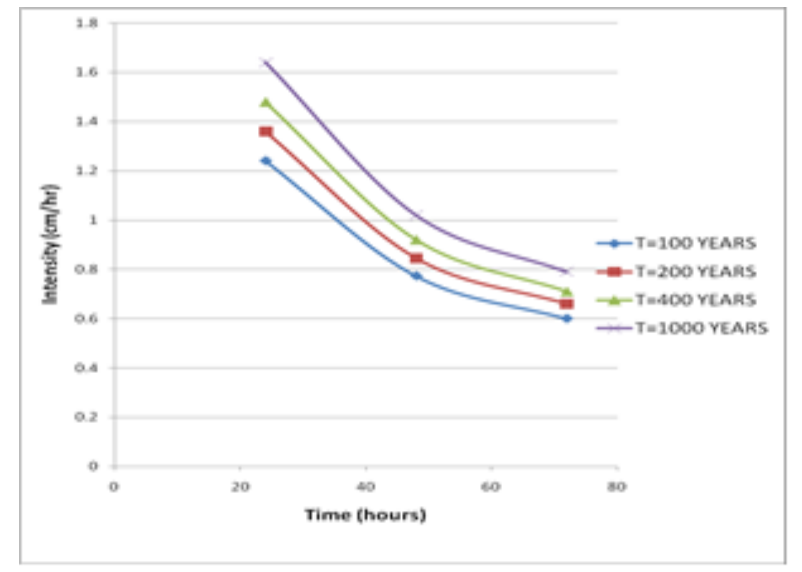

Fig. 2: IDF curves for Kallada River basin

\subsection{Maximum Flood}

Clark's method is used to determine the maximum flood. This method involves the preparation of isochrones as in Figure 3. Isochrones are lines that connect points of equal time of travel.The inter-isochronal areas $\left(A_{r}\right)$ are then determined using the GIS software and the corresponding inflows are obtained using equation 2 .

$$
I=\left(2.78 \times A_{r}\right) / t
$$

Where' $t$ ' represents time of travel and is dependent on the obtained time of concentration and number of interisochronal areas. The inflows are then routed using the Musckingum's method to obtain the maximum flood value. The Musckingum's method is based on equation 3.

$Q=C_{0} I_{1}+C_{1} I_{0}+C_{2} Q_{0}$

Where $\mathrm{Co}, \mathrm{C}_{1}$ and $\mathrm{C}_{2}$ are constants and take the values 0.27 , 0.57 and 0.17 respectively and are dependent on two factors, i.e., storage constant $(\mathrm{K})$ and a dimensionless factor ( $\mathrm{x}$ ). Value of ' $\mathrm{K}$ ' is taken as 0.2 (for natural channels) and ' $\mathrm{X}$ ' as 0.15 day. ' $\mathrm{I}$ ' represents inflow to the reservoir and ' $\mathrm{Q}$ ' represents outflow. 


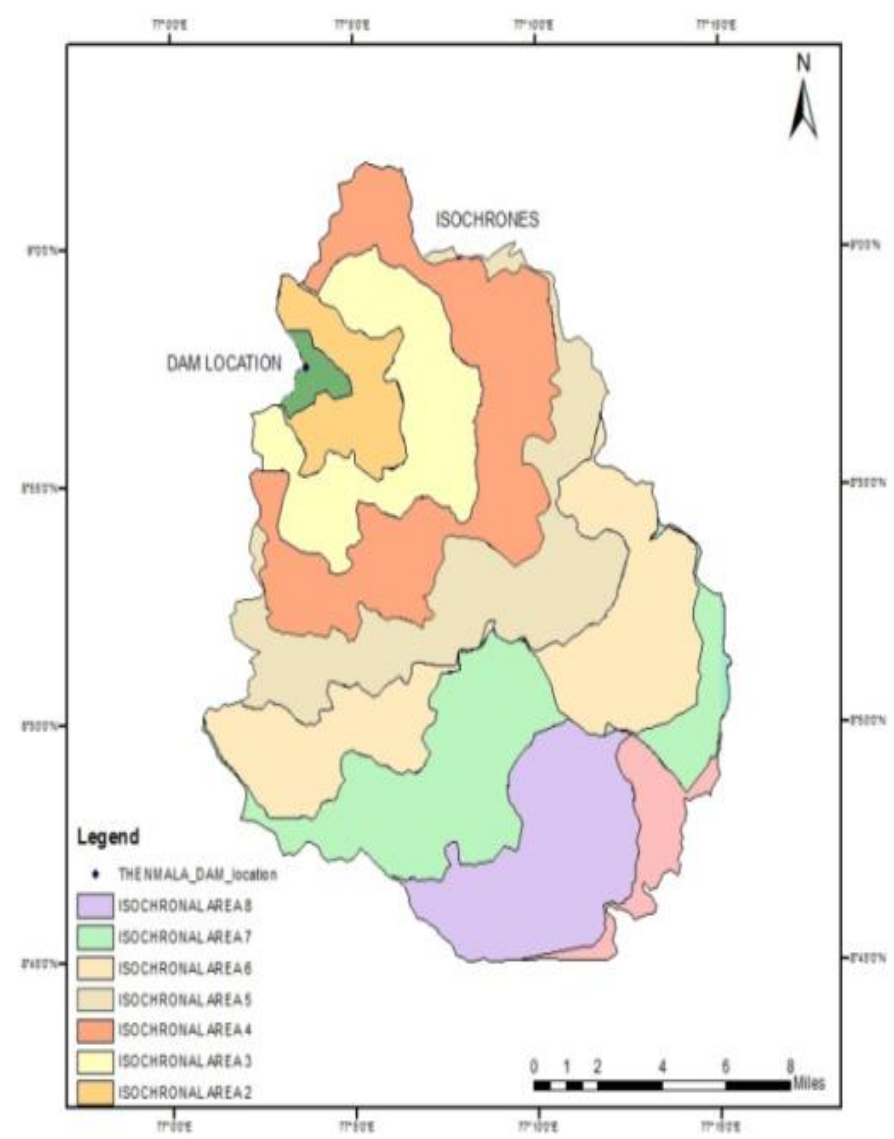

Fig. 3: Isochrones

\subsection{Flood routing}

Modified Pul's method is a flood routing technique to determine the peak flow attenuation that a hydrograph undergoes. To perform the routing, a relation between storage and outflow is calculated and plotted and is solved at each time step using the equation 4.

$\frac{\mathrm{S}_{2}}{\Delta \mathrm{t}}+\frac{\mathrm{O}_{2}}{2}=\left(\frac{\mathrm{S}_{1}}{\Delta \mathrm{t}}+\frac{\mathrm{o}_{1}}{2}\right)-\mathrm{O}_{1}+\left(\frac{\left(\mathrm{I}_{1}+\mathrm{I}_{2}\right)}{2}\right)$

Where ' $S$ ' represents storage of the reservoir, ' $O$ ', the outflow and 'I', the inflow.

\subsection{Analysis}

Upon providing the various inputs required by the software for the execution of the analysis, the software solves the unsteady flow equations as in Eqn. 5 and Eqn. 6 iteratively and generates a series of results including reservoir depletion values, water surface elevations corresponding to each sections, flood wave velocity, travel time, depth and area of inundation.

$\mathrm{A} \frac{\partial \mathrm{V}}{\partial \mathrm{x}}+\mathrm{VT} \frac{\partial \mathrm{V}}{\partial \mathrm{x}}+\mathrm{T} \frac{\partial \mathrm{y}}{\partial \mathrm{t}}-\mathrm{q}=0$ $\frac{\partial y}{\partial x}+\frac{V}{g} \frac{\partial V}{\partial x}+\frac{1}{g} \frac{\partial V}{\partial t}=S_{0}-S_{f}$

In this study, 43 cross sections are specified which upon interpolation is increased to 272. Cross section of the channel together with the corresponding flood plain sections are obtained from the ASTER digital elevation model using the ArcGIS software. The surface area of the reservoir is provided as reservoir description along with the respective elevations. The inflow hydrograph values obtained previously by Musckingum's method are given as inputs together with the various boundary conditions for the analysis.

\section{RESULTS AND DISCUSSIONS}

\subsection{Maximum Precipitation}

The magnitudes of maximum values of $24 \mathrm{hrs}, 48 \mathrm{hrs}$ and 72 hrs rainfall values are computed for each year during the data period of 1982-2011 and are shown in Table 1. The maximum intensities are then found out and are tabulated in Table 2. Also the time of concentration was found out to be $1.5 \mathrm{hrs}$. Using these values and adopting a return period of 1000 years (as for large hydraulic structures), the maximum precipitation is found as $396 \mathrm{~mm}$ with the help of the IDF curves that are plotted as shown in Figure 2.

Table 1: Maximum rainfall values

\begin{tabular}{cccc}
\hline \multirow{2}{*}{ Year } & \multicolumn{3}{c}{ Maximum precipitation $(\mathrm{mm})$} \\
\cline { 2 - 4 } & 24 hours & 48 hours & 72 hours \\
\hline 1982 & 107.4 & 128 & 154.2 \\
1983 & 145.4 & 154.6 & 155.8 \\
1984 & 86.8 & 134.1 & 165.5 \\
1985 & 87.2 & 120.6 & 173 \\
1986 & 80.8 & 120.8 & 146 \\
1987 & 99.4 & 173 & 197.2 \\
1988 & 84.6 & 131.2 & 138.4 \\
1989 & 112.2 & 119.4 & 169.8 \\
1990 & 97.4 & 152.4 & 167.6 \\
1991 & 147.2 & 201.2 & 319.6 \\
1992 & 268.6 & 345.4 & 357.6 \\
1993 & 131.6 & 192.4 & 274 \\
1994 & 162.4 & 214 & 251.4 \\
1995 & 97.2 & 147 & 161.4 \\
1996 & 99.2 & 151 & 215.4 \\
1997 & 131.6 & 130 & 159.2 \\
1998 & 174.8 & 282.2 & 330.4 \\
1999 & 123.2 & 181.4 & 244.2 \\
2000 & 201.4 & 222.7 & 264.2 \\
& & &
\end{tabular}




\begin{tabular}{cccc}
2001 & 128 & 147.6 & 187 \\
2002 & 153.2 & 212.6 & 231 \\
2003 & 73.4 & 95 & 134.6 \\
2004 & 66.8 & 121 & 149 \\
2005 & 79.4 & 120.8 & 132 \\
2006 & 134.2 & 162.4 & 191.4 \\
2007 & 160.2 & 170.4 & 177.8 \\
2008 & 95.2 & 119.6 & 136 \\
2009 & 112.6 & 160.2 & 181.8 \\
2010 & 180 & 260.4 & 283.8 \\
2011 & 106 & 107.2 & 114.4 \\
& & & \\
\hline
\end{tabular}

Using equation 2, the inflows to the reservoir are found out. These inflows as in table 3 are routed using equation 3 to get the instantaneous unit hydrograph ordinates. These IUH ordinates are first converted to 1 hour unit hydrograph ordinates by S-curve technique and are then converted to direct runoff ordinates, which is in turn converted to flood hydrograph ordinates by accounting the base flow. For the tabulations, an initial loss of $10 \mathrm{~mm}$ is assumed as per the Kallada irrigation report (1966) and the base flow rate is taken equal to 0.15 cumecs/ sq.km as per the Central Water Commission's flood estimation reportand is obtained as 79 cumecs. Figure 4 shows the obtained flood hydrograph and the value of the maximum flood entering the reservoir is found as 4589.42 cumecs.

\subsection{Maximum flood}

Table 2 : Maximum rainfall intensities

\begin{tabular}{|c|c|c|c|c|}
\hline \multicolumn{5}{|c|}{ Maximum rainfall intensities $(\mathrm{cm} / \mathrm{hr})$} \\
\hline Return period & 100 years & 200 years & 400 years & 1000 years \\
\hline Duration & & & & \\
\hline 24 hours & 1.240 & 1.360 & 1.480 & 1.64 \\
\hline 48 hours & 0.773 & 0.846 & 0.920 & 1.02 \\
\hline 72 hours & 0.600 & 0.660 & 0.710 & 0.79 \\
\hline
\end{tabular}

Table 3: Reservoir inflow

\begin{tabular}{ccc}
\hline Time (minutes) & Interisochronal areas $\left(\mathrm{km}^{2}\right)$ & Inflow $(\mathrm{cmecs})$ \\
\hline 0 & & 0 \\
10 & 0 & 90.880 \\
20 & 5.449 & 223.319 \\
30 & 26.657 & 341.606 \\
40 & 61.440 & 406.867 \\
50 & 97.570 & 273.912 \\
60 & 110.108 & 254.097 \\
70 & 91.402 & 189.253 \\
80 & 79.423 & 133.317 \\
90 & 52.941 & 33.023 \\
\hline
\end{tabular}

\subsection{Reservoir Routing}

The modified Pul's method makes use of equation 4 for the routing process anda time - elevation - flood outflow relation is obtained, from which it can be understood that the spillway providedis sufficient.

\subsection{Dam Break Analysis}

For the analysis using BOSS DAMBRK software, several inputs are given which includes the reach description which is obtained from ASTER DEM, the various boundary conditions which involve several factors like time to dam failure, routing period, slope of channel downstream etc..., reservoir description as surface areas corresponding to different elevations and breach description which includes breach width, breach side slope, final breach elevation etc...
After the analysis using the software, a number of outputs are obtained. Table 4 shows water surface elevations at various selected cross sections. 


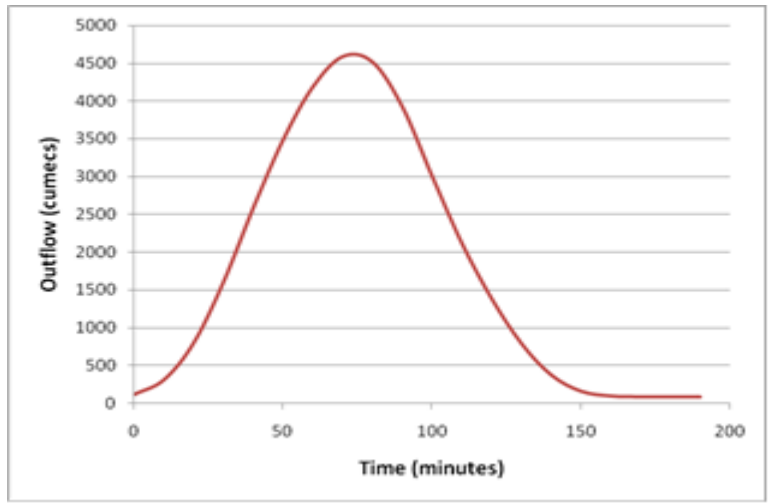

Fig. 4: Flood hydrograph

Table 4: Water surface elevations

\begin{tabular}{cc}
\hline $\begin{array}{c}\text { River cross section } \\
\text { location }(\mathrm{km})\end{array}$ & Water surface elevation $(\mathrm{m})$ \\
\hline 0 & 85.09 \\
0.437 & 68.40 \\
0.560 & 65.00 \\
0.630 & 64.750 \\
0.840 & 63.730
\end{tabular}

$\begin{array}{ll}0.980 & 61.370 \\ 2.800 & 51.400 \\ .313 & 42.010 \\ 5.192 & 36.150 \\ 5.875 & 32.880 \\ 6.813 & 30.770 \\ 8.833 & 29.660 \\ 11.200 & 27.740 \\ 13.588 & 19.310 \\ 14.000 & 18.110 \\ 38.000 & 10.840 \\ 69.000 & 7.470\end{array}$

Table 5 briefs about the flood wave velocity, travel time and area of inundation, which are the required outputs of the dam break analysis. The maximum velocity of $1.72 \mathrm{~m} / \mathrm{s}$ occurred at a distance of $11.2 \mathrm{~km}$ and a minimum velocity of $0.06 \mathrm{~m} / \mathrm{s}$ at a distance of $14 \mathrm{~km}$ downstream of the dam section.

Table 5: Results of dam break analysis

\begin{tabular}{cccccc}
\hline $\begin{array}{c}\text { River cross section } \\
\text { location(m) }\end{array}$ & $\begin{array}{c}\text { Flow velocity } \\
\text { (m/s) }\end{array}$ & $\begin{array}{c}\text { Channel flow } \\
\text { area (sq.m) }\end{array}$ & $\begin{array}{c}\text { Left flood } \\
\text { plain area } \\
\text { (sq.m) }\end{array}$ & $\begin{array}{c}\text { Right flood } \\
\text { plain area } \\
\text { (sq.m) }\end{array}$ & $\begin{array}{c}\text { Time } \\
\text { (minutes) }\end{array}$ \\
\hline 0 & & & & & \\
0.9 & 39 & 0 & 0 & 0 \\
0.437 & 1.38 & 25 & 0 & 0 & 5.277 \\
0.560 & 1.54 & 18 & 1 & 4 & 1.33 \\
0.630 & 1.49 & 15 & 1 & 8 & 0.783 \\
0.700 & 1.44 & 13 & 1 & 11 & 0.81 \\
0.770 & 1.40 & 10 & 1 & 14 & 0.833 \\
0.840 & 1.36 & 8 & 1 & 16 & 0.857 \\
0.910 & 1.32 & 6 & 2 & 19 & 0.883 \\
0.980 & 1.29 & 5 & 2 & 21 & 0.904 \\
2.800 & 1.46 & 24 & 0 & 0 & 20.77 \\
4.313 & 1.13 & 21 & 0 & 0 & 22.31 \\
5.192 & 1.68 & 21 & 0 & 0 & 8.72 \\
5.875 & 1.35 & 26 & 0 & 0 & 8.432 \\
6.813 & 0.98 & 36 & 0 & 0 & 15.952 \\
8.833 & 0.89 & 21 & 0 & 19 & 37.82 \\
11.200 & 1.72 & 20 & 0 & 0 & 22.93 \\
13.588 & 1.35 & 25 & 0 & 1 & 29.48 \\
14.000 & 0.06 & 304 & 0 & 237 & 114.44 \\
38.000 & 0.48 & 73 & 0 & 0 & 833.33 \\
69.000 & 0.50 & 70 & 0 & 0 & 1033.33
\end{tabular}

\section{CONCLUSIONS}

The dam break analysis of Thenmala Dam is carried out using BOSS DAMBRK software. The maximum precipitation is found out to be $396 \mathrm{~mm}$ and the corresponding flood to be $4589.42 \mathrm{~m}^{3} / \mathrm{s}$. The spillway 
provided is also found out to be adequate. The total time of travel of dam break flood wave is found out to be 35.98 hours. Various other outputs such as flood wave velocity, area and depth of inundation etc... are also obtained so that adequate warnings can be provided to the public during emergencies like flood.

\section{REFERENCES}

[1] G. Al Mashidani, Pande, B.B Lal, M Fattah, "A simple version of Gumbel's Method for flood estimation", Hydrological Science Bulletin, pp. 373 $-341,1978$

[2] Guang-Te and V P Singh, "Muskingum method with variable parameters for flood routing in channels", Journal of Hydrology, 134, pp. 57 -76, 1992

[3] David C. Froehlich, "Peak outflow from breached embankment dam", Journal of Water Resources Planning and Management, 121, pp. 90-97, 1995

[4] F. W. L. Kho, P. L. Law, S. H. Lai, Y.W. Oon, L. H. Ngu,H.S.Ting, "Quantitative Dam Break Analysis on a Reservoir Earth Dam”, International Journal of Environment, Science and Technology,6 (2), pp. $203-210,2009$.

[5] "Flow estimation and routing", Urban storm water management manual, pp. 14-1 to 14-30 